\title{
Điều tra nhu cầu và khả năng tìm kiếm phòng trọ của sinh viên trường Đại học Vinh \\ (Nghiên cứu mẫu điều tra từ sinh viên ngành Sư phạm Địa lí)
}

\author{
Lương Thị Thành Vinh*, Nguyễn Thanh Phong \\ Khoa Địa lí - Quản lí Tài nguyên, Truờng Đại học Vinh, 182 Lê Duẩn, Tp. Vinh, Nghệ An, Việt Nam \\ Nhận ngày 06 tháng 6 năm 2016 \\ Chỉnh sửa ngày 21 tháng 6 năm 2016; Chấp nhận đăng ngày 24 tháng 3 năm 2017
}

\begin{abstract}
Tóm tắt: Trên cơ sở khảo sát điều tra sinh viên của Trường Đại học Vinh, bài báo đã phân tích đặc điểm sinh viên ngoại trú, nhu cầu và khả năng tìm kiếm phòng trọ cũng như khả năng đáp ứng phòng trọ của các khu vực xung quanh trường, từ đó đề xuất giải pháp hỗ trợ sinh viên tìm kiếm phòng trọ một cách nhanh chóng và thuận tiện.
\end{abstract}

Tù khóa: Sinh viên, Phòng trọ, Đại học Vinh.

\section{1. Đặt vấn đề}

Trường Đại học Vinh đang có những bước tiến quan trọng để khẳng định vị trí một trong 16 trường đại học trọng điểm quốc gia. Với tổng số khoảng 44.000 học viên, và sinh viên (trong đó sinh viên chính quy khoảng 21.000 người), trung bình hàng năm trường tuyển sinh thêm 5000 sinh viên chính quy. Do kí túc xá có sức chứa nhỏ chỉ đáp ứng được $0,01 \%$ nhu cầu, nên đa phần sinh viên ở ngoại trú, vì thế nhu cầu tìm kiếm phòng trọ của sinh viên rất lớn. Tuy nhiên, đối với phần lớn sinh viên, đặc biệt là sinh viên mới vào trường đến từ nhiều địa phương khác nhau, chưa quen với địa bàn thành phố Vinh việc tìm kiếm phòng trọ gặp nhiều khó khăn. Mặt khác thông tin về phòng trọ tương đối manh mún, sinh viên tìm phòng trọ chủ yếu qua giới thiệu của người quen hoặc tự

\footnotetext{
* Tác giả liên hệ. ĐT: 84-919558313.

Email: hvhaivinh404@gmail.com
}

đi tìm nên mất nhiều thời gian và không có nhiều lựa chọn.

Chính vì vậy, việc nghiên cứu khảo sát đặc điểm, nhu cầu phòng trọ và khả năng đáp ứng phòng trọ cho sinh viên Trường Đại học Vinh có ý nghĩa thiết thực. Đây là cơ sở để nhà trường quản lý sinh viên ngoại trú, và hỗ trợ sinh viên tìm phòng trọ một cách nhanh chóng, tiết kiệm và hiệu quả.

\section{Cơ sở tài liệu và phương pháp nghiên cứu}

Co sở tài liệu: Để khảo sát nhu cầu và khả năng đáp ứng phòng trọ cho sinh viên trường Đại học Vinh cũng như tiến tới xây dựng bản đồ trực tuyến cung cấp thông tin phòng trọ, các nguồn tại liệu sau đã được sử dụng: (1) Các số liệu khảo sát thực địa về thông tin phòng trọ tại các điểm tập trung phòng trọ xung quanh trường Đại học Vinh. Các phiếu điều tra xã hội học khảo sát nhu cầu phòng trọ và khả năng tìm 
kiếm và đáp ứng phòng trọ cho sinh viên, (2) Các tài liệu và số liệu về điều kiện tự nhiên, kinh tế - xã hội, hệ thống phòng trọ của các phường xung quanh trường Đại học Vinh [1-4]; (3) Các tài liệu, số liệu, thông tin về Trường Đại học Vinh [5-7];

\section{Phưong pháp nghiên cưu}

- Phương pháp thu thập, xử lý và tổng hợp tài liệu gồm các bước sau:

+ Xác định đối tượng, phạm vi và các nội dung thu thập tài liệu theo mục tiêu của đề tài. Khu vực nghiên cứu được giới hạn trong khu vực xung quanh Trường Đại học Vinh, cụ thể bao gồm các phường : Bến Thủy, Trung Đô và Trường Thi.

+ Tiến hành thu thập tài liệu về trường đại học Vinh, về sinh viên của trường, về điều kiện kinh tế - xã hội khu vực xung quanh trường và tình hình các phòng trọ tại thành phố Vinh.

+ Xử lí, phân tích và tổng hợp tài liệu trên phần mềm Excel.

- Phương pháp thực địa: Thực hiện khảo sát từng phòng trọ, sử dụng thiết bị GPS xác định chính xác tọa độ của các phòng trọ để đưa lên bản đồ.

- Phương pháp điều tra xã hội học: Đối với sinh viên được tiến hành cho sinh viên sư phạm Địa lí 3 khóa 54,55 và 56 với tổng số phiếu điều tra là 100 . Trong đó, sinh viên khóa 54 có 39 bạn, $k 55$ có 36 bạn và $k 56$ có 30 bạn. Việc điều tra thông tin sinh viên dựa vào 3 khía cạnh: thông tin về sinh viên, thông tin về phòng trọ hiện thời và thông tin về nhu cầu phòng trọ. Thông tin sinh viên bao gồm các thông tin sau: họ và tên, lớp, mã số sinh viên, số điện thoại, mức chi tiêu trung bình một tháng, số lần chuyển trọ và lí do chuyển trọ. Về thông tin phòng trọ có hai lựa chọn cho sinh viên ở trọ và không ở trọ. Đối với sinh viên ở trọ thì các thông tin cần thiết là: Địa chỉ phòng trọ, tên chủ trọ, số điện thoại, số phòng trong dãy trọ, phòng trọ ở được bao nhiêu người...

Đối với các phòng trọ: được tiến hành với 50 chủ trọ để lấy thông tin về: địa chỉ phòng trọ, tên chủ trọ, số điện thoại, số phòng trong dãy trọ, phòng trọ ở được bao nhiêu người...

\section{Kết quả nghiên cứu và thảo luận}

\section{1. Đặc điểm sinh viên và nhu cầu ở trọ của sinh viên ngoại trú}

\subsubsection{Công tác quản lí sinh viên}

a. Thông tin tổng quan về Trường Đại học Vinh

Trường Đại học Vinh có tiền thân là Trường Đại học Sư phạm Vinh, được thành lập từ năm 1959, với gần 60 năm xây dựng và trưởng thành, hiện nay Trường là cơ sở đào tạo đại học đa ngành, đa cấp ở khu vực Bắc Trung Bộ, cung cấp nguồn nhân lực chất lượng cao và thích ứng nhanh với thế giới việc làm; là trung tâm nghiên cứu khoa học, ứng dụng và chuyển giao công nghệ, phục vụ sự nghiệp phát triển kinh tế - xã hội của khu vực và cả nước; hướng đến là trường đại học trọng điểm quốc gia, có một số ngành đạt tiêu chuẩn quốc tế. Từ năm 1991, Trường đã mở rộng và phát triển hàng chục mã ngành ngoài sư phạm để không ngừng đáp ứng các yêu cầu của xã hội về nhân lực trên các lĩnh vực: kinh tế, nông, lâm, ngư nghiệp, xây dựng, điện tử viễn thông, luật, công nghệ thông tin... Đến nay, Nhà trường đã đào tạo nhiều bậc học, ngành học khác nhau với 15 chuyên ngành tiến sĩ, 31 chuyên ngành thạc sĩ; đào tạo 50 ngành kỹ sư, cử nhân; đào tạo học sinh trung học phổ thông chuyên với 6 môn chuyên (Toán, Vật lý, Hóa học, Sinh học, Tin học và Tiếng Anh). Quy mô tuyển sinh của Trường ở các hệ, bậc học, ngành, hình thức đào tạo không ngừng tăng lên. Hiện nay toàn Trường có khoảng 44.000 học sinh, sinh viên, học viên. Ngoài ra, Trường còn liên kết với các cơ sở giáo dục trong và ngoài nước đào tạo các trình độ đại học và sau đại học nhằm đáp ứng nhu cầu nguồn nhân lực có trình độ cao cho đất nước [5].

b. Công tác quản lí học sinh, sinh viên của Trường Đại học Vinh

Nhà trường thường xuyên xây dựng kế hoạch và thực hiện đầy đủ các nội dung, biện 
pháp giáo dục tư tưởng chính trị, đạo đức lối sống cho sinh viên theo quy định của Bộ Giáo dục và Đào tạo như: Tổ chức "Tuần sinh hoạt công dân - học sinh, sinh viên" vào đầu khóa học và đầu mỗi năm học; Tổ chức các buổi nói chuyện ngoại khóa, các cuộc thi tìm hiểu do nhà trường và cấp trên phát động; Tổ chức cho sinh viên học tập và quán triệt Nghị quyết của Đảng; Duy trì tổ chức sinh hoạt lớp định kỳ từ ngày 01 đến ngày 10 hàng tháng... Các hoạt động trên nhằm nâng cao nhận thức của sinh viên về đường lối, chủ trương của Đảng, chính sách, pháp luật của Nhà nước; Giúp cho sinh viên nắm được tình hình kinh tế, chính trị, xã hội trong nước, khu vực và quốc tế; Giúp sinh viền hiểu rõ quyền lợi, nghĩa vụ, ý thức trách nhiệm của công dân -sinh viên thông qua việc tuyên truyền, phổ biến pháp luật, các quy chế, quy định về đào tạo, về công tác sinh viên của Bộ Giáo dục và Đào tạo và của nhà trường; Đặc biệt, giúp sinh viên nắm bắt được phương hướng, nhiệm vụ của năm học, hiểu rõ nhiệm vụ của người học nhằm đáp ứng được nhu cầu của xã hội.

Xây dựng một số mô hình hiệu quả trong công tác quản lý sinh viên nội - ngoại trú, bảo đảm an ninh, trật tự trường học, giáo dục an toàn giao thông, phòng, chống tội phạm và tệ nạn xã hội. Trường Đại học Vinh là đơn vị dẫn đầu trong mô hình quản lý sinh viên tạm trú, luôn phối hợp chặt chẽ với công an và chính quyền các cấp để đưa ra nhiều giải pháp nhằm quản lý, giáo dục sinh viên. Nhà trường đã phân công 27 cán bộ chuyên trách quản lý sinh viên của trường phụ trách 69 khối, phường có sinh viên tạm trú để phối hợp với Ban cán sự các khối phố kiểm tra, khảo sát, lập hồ sơ theo dõi sinh viên tạm trú. Đồng thời, thành lập các tổ tự quản sinh viên tại địa bàn dân cư để nắm bắt kịp thời tình hình sinh viên tạm trú: Hình thành Tồ sinh viên tự quản theo đơn vị khối phố, với tinh thần "3 tự chủ": tự quản lý, tự giáo dục, tự phục vụ nhằm thu hút sinh viên tham gia các hoạt động xã hội ở địa phương, xem khối phố là đơn vị cơ sở trực tiếp quản lý sinh viên ngoại trú. Định kỳ, tổ chức Hội nghị về công tác an ninh trường học với công an tỉnh Nghệ An, công an thành phố Vinh, công an các phường phụ cận và lãnh đạo các phường xã, khối trưởng các khối dân phố có đông số lượng sinh viên tạm trú [6].

3.1.2. Đặc điểm sinh viên và nhu cầu ở trọ của sinh viên ngoại trú

a. Một số đặc điểm cơ bản của sinh viên đại học Vinh

Trong tổng số 44.000 học viên, sinh viên có 21.000 sinh viên chính quy, là đối tượng có nhu cầu ở trọ thường xuyên trong suốt 4 - 5 năm của quá trình học đại học. Đây là đối tượng nghiên cứu chính của đề tài. Về đặc điểm xuất thân, hơn $65 \%$ sinh viên của trường đến từ nông thôn, miền núi (trong đó sinh viên là con em dân tộc chiếm trên $20 \%$ ); sinh viên đông nhất thuộc tỉnh Nghệ An (hơn 58\%); đông thứ hai là tỉnh Hà Tĩnh (26\%), thứ 3 là tỉnh Thanh Hóa $(11 \%)$, còn lại là từ các tỉnh khác (dưới $5 \%$ ). Trong số sinh viên thuộc tỉnh Nghệ An chỉ có gần $10 \%$ là sinh viên có hộ khẩu tại thành phố Vinh, còn lại là sinh viên đến từ các huyện, thị trong tỉnh [7]. Như vậy, sinh viên đến từ nhiều địa phương khác nhau, đại đa số là con em nông thôn và miền núi, điều này gây khó khăn cho sinh viên trong quá trình tìm kiếm phòng trọ, lựa chọn những phòng trọ phù hợp với hoàn cảnh của mình, cũng như quá trình thích nghi với môi trường sống mới. Nhiều sinh viên có biểu hiện ngại ngần, khép kín, tự cô lập mình do không quen với nơi ở mới, môi trường học tập mới. Sinh viên của Trường có tỉ lệ nữ nhiều hơn nam (tî̉ lệ 61:39), với đặc thù của giới thì sinh viên nữ thường có xu hướng ở một mình và ở ít người hơn, trong khi sinh viên nam có xu hướng ở ghép nhiều hơn. Điều này sẽ ảnh hưởng đến việc lựa chọn loại phòng trọ cũng như bạn cùng trọ. Nhìn chung, với phần đa sinh viên có điều kiện sống trung bình nên số lượng phòng ở ghép khá lớn.

\section{điều tra \\ b. Đặc điểm của sinh viên theo kết quả}

Trong số 100 sinh viên được điều tra thì có $90 \%$ sinh viên là phải thuê phòng trọ, $9 \%$ sinh viên ở cùng gia đình, $1 \%$ sinh viên ở cùng anh em và người thân. Tuy nhiên, trên thực tế thì số 
sinh viên phải thuê trọ khá lớn, trong đó có khoảng $0.01 \%$ sinh viên ở kí túc xá của trường [7].

Các chỉ tiêu điều tra cụ thể được thể hiện dưới đây:

- Về múc chi tiêu: Trong 100 mẫu phiếu, tỉ lệ sinh viên có mức chi tiêu trung bình/tháng tập trung phần lớn ở mức $1-1,5$ triệu/tháng (53\%). Mức chi tiêu từ $1,5-2$ triệu/tháng chiếm $18 \%$, mức chi tiêu trên 2 triệu/tháng chỉ chiếm $5 \%$. Còn lại là mức chi tiêu dưới 1 triệu/tháng. Như vậy, nhìn vào mức chi tiêu có thể thấy sinh viên của nhóm điều tra nói riêng và sinh viên Trường Đại học Vinh nói chung phần lớn là sinh viên có mức sống trung bình, điều kiện sống của phần đa sinh viên là khó khăn. Điều này sẽ ảnh hưởng đến khả năng chi trả cho việc thuê phòng trọ của sinh viên.

- Về số lần chuyển trọ: Một đặc điểm dễ nhận thấy là số lần chuyển trọ của sinh viên trong thời gian đi học tương đối ít, $83 \%$ sinh viên chuyển trọ dưới 3 lần, $13 \%$ chuyển trọ từ 3-5 lần, có có $2 \%$ chuyển trọ trên 5 lần. Như vậy, tính ổn định trong việc thuê phòng trọ của sinh viên là tương đối cao.

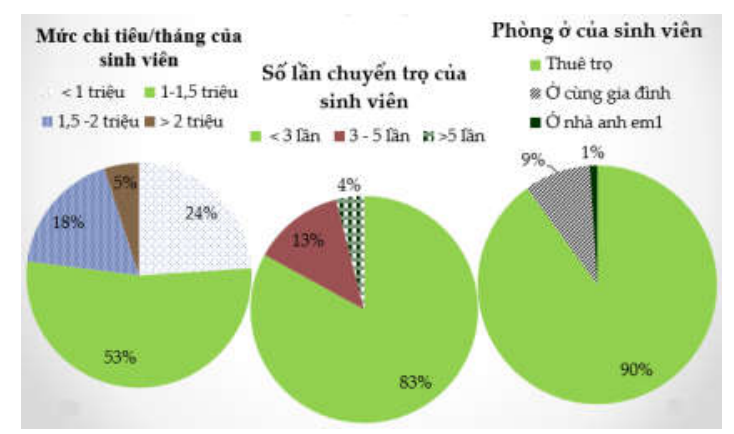

Hình 1. Biểu đồ đặc điểm sinh viên và nhu cầu phòng trọ.

- Về các phòng trọ của sinh viên đã thuê

+ Phạm vi phân bố: theo số liệu khảo sát của mẫu điều tra thì phạm vi phân bố của sinh viên chủ yếu tập trung ở các phường xung quanh Trường Đại học Vinh. Trong đó, ở phường Bến Thủy có mật độ tập trung đông nhất là $47 \%$, phường Trung Đô đông thứ 2 với $37 \%$, phường Trường Thi chỉ có $13 \%$ sinh viên.
Và chỉ có $3 \%$ sinh viên sinh sống ở những khu vực khác.

+ Diện tích phòng trọ đang được thuê: phòng trọ có diện tích lớn hơn $15 \mathrm{~m}^{2}$ chiếm $24 \%$ trong đó có $4 \%$ diện tích phòng trên $60 \mathrm{~m}^{2}$ là các phòng ở chung cư, dưới $10 \mathrm{~m}^{2}$ là $26 \%$, từ 10 $15 \mathrm{~m}^{2}$ chiếm $56 \%$.

+ Tỉ lệ người ở trong một phòng trọ: đông nhất vẫn là số sinh viên ở một mình, chiếm $62,2 \%$, tiếp đến sinh viên ở đôi là $23 \%$, còn phòng trọ có 3 người ở thấp nhất là $12 \%$, qua số liệu khảo sát ta thấy nhu cầu ở độc lập của sinh viên khá cao.

+ Về giá phòng trọ đang thuê: giá dưới 300.000 /người chiếm $10 \%$, từ 300 500.000 /người chiếm $19 \%, \quad 500$ 700.000 /người chiếm $39 \%$ và trên 700.000 /người chiếm $32 \%$ với tỉ lệ phòng trọ không khép kín chiếm $67,8 \%$. Như vậy, giá phòng trọ nhìn chung cao hơn so với mức sống của sinh viên và khả năng đáp ứng dịch vụ tối thiểu còn hạn chế. Bên cạnh đó có những phòng trọ có mức điện cá biệt là 4.000 đồng/kg, (mức điện trung bình phải trả cho một số điện là 3.000 đồng $/ \mathrm{kg}$ ). Mức tiêu thụ điện trung bình là 50.000 - 60.000 đồng/sinh viên/tháng, còn mức tiêu thụ nước trung bình từ $30.000-40.000$ đồng/sinh viên/tháng. Khả năng đáp ứng nhu cầu sử dụng internet khá tốt, có tới $65 \%$ phòng trọ có wifi.

+ Mức độ an toàn của các phòng trọ: Theo khảo sát điều tra có $56 \%$ phòng trọ đảm bảo an toàn, 39\% mức độ an ninh ở phòng trọ bình thường và chỉ có $3 \%$ nhận thấy mức độ không an toàn của phòng trọ. Tuy nhiên, trên thực tế có thể thấy mức độ không an toàn của phòng trọ ở một số khu vực xung quanh trường đại học Vinh cao hơn so với tỉ lệ này. Ví dụ: Khu vực Núi Quyết, chợ Quyết, khu vực cuối đường Nguyễn Văn Trỗi, trục đường Hoàng Thị Loan và Phong Đình Cảng.

+ Về nhu cầu phòng trọ của sinh viên thì mức độ không cần thiết là $6 \%$, mức độ bình thường: $54 \%$ và mức độ rất cần thiết là $40 \%$

+ Khả năng tìm kiếm phòng trọ của sinh viên: $63 \%$ sinh viên nhận thấy tìm kiếm phòng 
trọ là bình thường, $10 \%$ thấy việc tìm kiếm phòng trọ là dễ dàng và có $27 \%$ sinh viên cho rằng việc tìm kiếm phòng trọ là khó.

+ Phương pháp tìm kiếm: $66 \%$ sinh viên tự đi tìm phòng trọ, có $9 \%$ biết được phòng thông qua quảng cáo, $17 \%$ tìm kiếm phòng thông qua internet, và số còn lại tìm kiếm theo các phương pháp khác.

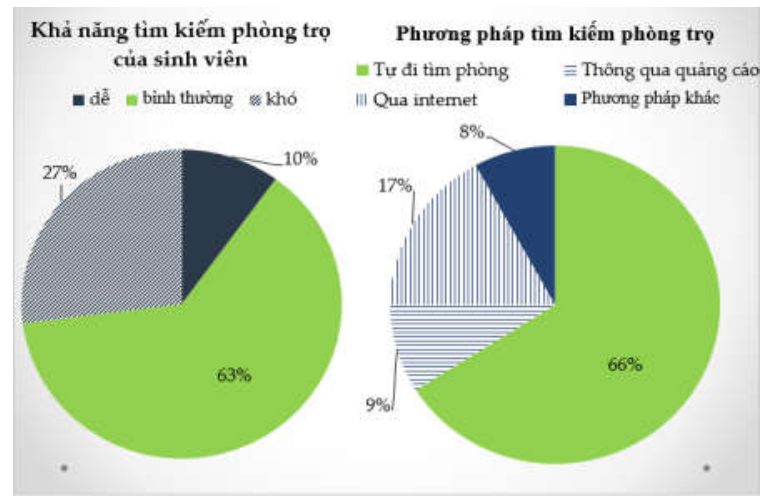

Hình 2. Biểu đồ khả năng tìm kiếm phòng trọ của sinh viên Trường Đại học Vinh.

\section{2. Đặc điểm mạng lưới phòng trọ khu vục} xung quanh truờng Đại học Vinh

\subsubsection{Khái quát khu vự nghiên cứu}

Do sinh viên Trường Đại học Vinh phần lớn tập trung ở khu vực xung quanh trường (hơn $90 \%$ sinh viên chính quy) nên khu vực nghiên cứu được giới hạn trong phạm vi 3 phường: Bến Thủy, Trung Đô và Trường Thi.

\section{a. Phường Bến Thủy}

Phường Bến Thủy (TP Vinh - Nghệ An) có diện tích tự nhiên $2,91 \mathrm{~km} 2$, dân số hơn 17.000 người, với 3.404 hộ dân [5] phía Nam giáp tỉnh Hà Tĩnh được ngăn cách bởinhánh chính của sông Lam.Trên địa bàn phường có nhiều đầu mối giao thông quan trọng.

Với lợi thế diện tích rộng, dân cư đông đúc, có trường Đại học Vinh, chợ khu vực và nhiều cơ quan, xí nghiệp đóng trên địa bàn, giai đoạn 2005 - 2008, phường Bến Thủy tiếp tục chuyển dịch cơ cấu kinh tế theo hướng thương mại dịch vụ, tạo điều kiện để tiểu thủ công nghiệp - xây dựng và nông nghiệp đô thị phát triển ổn định. Tồng giá trị sản xuất ngoài quốc doanh ước thực hiện trong năm 2008 là 168 tỷ, tốc độ tăng trưởng kinh tế bình quân 3 năm (2006 2008) $12,5 \%$, hộ giàu và hộ khá tăng $15 \%$, hộ nghèo giảm còn $2,72 \%$.

An ninh chính trị - trật tự an toàn xã hội luôn được đảm bảo. Phường đã xây dựng và triển khai thực hiện một số mô hình: "Khối phố đảm bảo ANTT và văn minh đô thị"; "Khối phố từ có đến không ma túy"; "Quản lý học sinh, sinh viên ngoại trú"; "Quản lý bán vé xổ số, chống bán số đề"... Với những thành tích nổi bật trên, năm 2007, cán bộ và nhân dân phường Bến Thủy được Bộ Công an tặng cờ "Đơn vị dẫn đầu phong trào toàn dân bảo vệ ANTQ" [1].

\section{b. Phường Trung Đô}

Phường Trung Đô có tổng diện tích đất tự nhiên 284,3 ha, nằm ở cửa ngõ phía Đông Nam thành phố Vinh, nơi chiếm giữ nhiều đầu mối giao thông quan trọng, thuận lợi cho việc phát triển kinh tế, văn hóa và du lịch, dịch vụ. Phường được giới hạn bởi cầu Bến Thủy, phía Đông - Nam nhìn ra dòng sông Lam, tiếp giáp với huyện Nghi Xuân (Hà Tĩnh); phía Tây giáp phường Hồng Sơn và Quảng trường Hồ Chí Minh; phía Nam giáp xã Hưng Lợi (huyện Hưng Nguyên); phía Bắc giáp phường Trường Thi [2]

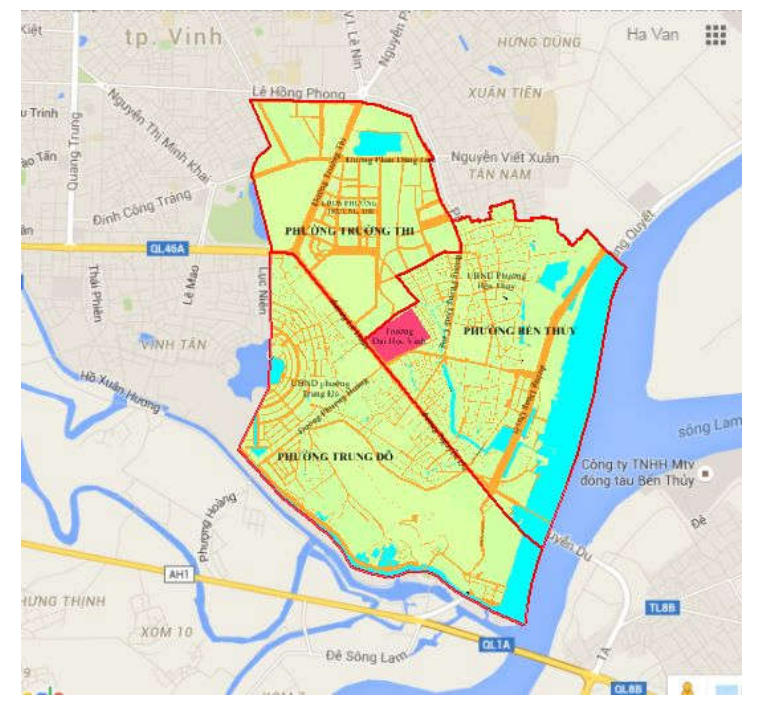

Hình 3. Sơ đồ khu vực nghiên cứu. 


\section{c. Phường Trường Thi}

Phường Trường Thi - Thành phố Vinh được thành lập ngày 21 tháng 8 năm 1982, có diện tích 1,94 km2 trên cơ sở sáp nhập các bộ phận dân cư và diện tích của các phường Hưng Bình, Hưng Dũng, Bến Thuỷ, Trung Đô. Khi mới thành lập, dân số của phường chỉ có 1.285 người, gồm 275 hộ, hiện nay toàn phường có hơn 15.729 người, 3.472 hộ, được quy hoạch thành 17 khối dân cư.

Phường Trường Thi là phường trung tâm của thành phố Vinh, nơi đóng đô của nhiều cơ quan đầu não của tỉnh và thành phố. Phường có tốc độ đô thị hóa nhanh và phát triển toàn diện trên các lĩnh vực kinh tế, góp phần đưa tổng thu ngân sách tăng đều hàng năm. Trong 6 tháng đầu năm 2014 , tổng thu ngân sách trên địa bàn đạt gần 4,5 tỷ đồng; tổng thu thuế Nhà nước đạt gần 4,8 tỷ đồng [3].

3.2.2. Điều tra khả năng đáp úng nhu cầu của mang lưới phòng trọ khu vục xung quanh Trường Đại hoc Vinh

a. Đặc điểm của mạng lưới phòng trọ

Tính đến thời điểm năm 2015, cả 3 phường có mật độ tập trung sinh viên của Trường Đại học Vinh cao nhất là phường Bến Thủy, phường Trường Thi và phường Trung Đô có 5043 phòng trọ thuộc 943 chủ trọ. Trong đó, phường Bến Thủy có số phòng trọ nhiều nhất 2962 phòng (chiếm 58\%), phường Trung Đô xếp thứ 2 với 1350 phòng trọ (chiếm 27\%). Phường Trường Thi có số phòng trọ ít nhất trong 3 phường với số phòng trọ là 731 phòng (chiểm 15\%); Do phường Trường Thi có diện tích dành cho đất quân đội, đất công chiếm tỉ lệ lớn. Mật độ dân cư khá cao nên tỉ lệ phòng trọ cho sinh viên ở khu vực này thấp.

Bảng 1. Thống kê số lượng phòng trọ theo các phường xung quanh Trường Đại học Vinh năm 2015

\begin{tabular}{llll}
\hline Phường & $\begin{array}{l}\text { Số chủ } \\
\text { trọ }\end{array}$ & Số phòng trọ & $\begin{array}{l}\text { Tỉ lệ } \\
\text { phòng trọ }\end{array}$ \\
\hline Bến Thủy & 432 & 3162 & 58 \\
Trung Đô & 275 & 1350 & 27 \\
Trường Thi & 236 & 731 & 15 \\
Tổng số & 943 & 5043 & 100 \\
\hline
\end{tabular}

Nguồn: Khảo sát điều tra phòng trọ, Tỉnh Đoàn Nghệ An [4] b. Điều tra khả năng đáp ứng nhu cầu ở trọ cho sinh viên

Khảo sát phiếu điều tra xã hội học thí điểm với 50 chủ hộ, với các thông tin liên quan đến chủ trọ, phòng trọ và khả năng đáp ứng nhu cầu của phòng trọ.

- Thu nhập của chủ trọ: đối với nguồn thu nhập từ việc cho thuê trọ, không có hộ nào thu dưới 1 triệu, thu nhập từ phòng trọ khoảng 1-3 triệu chiếm $8 \%, 3-5$ triệu chiếm $34 \%$, và trên 5 triệu chiếm giá trị lớn nhất là $58 \%$. Từ đó có thể thấy hoạt động cho thuê phòng trọ tạo ra nguồn thu nhập chính của chủ trọ.

- Diện tích của phòng trọ: mặt bằng chung là các phòng có diện tích từ 10-15 m2 (50\%), các phòng có diện tích lớn hơn $15 \mathrm{~m} 2$ chiếm $38 \%$, và có rất ít phòng có diện tích nhỏ dưới $10 \mathrm{~m} 2(12 \%)$.

- Về số phòng trong một dãy trọ: nhà trọ có phòng trọ cho thuê dưới 5 phòng chiếm $53 \%$, nhà trọ có từ $5-10$ phòng cho thuê chiếm $26 \%$, còn lại là các phòng trọ có số phòng cho thuê trên 10 phòng. Điều này cho thấy mức độ tập trung đông sinh viên trong một dãy trọ khá cao. Mặt tích cực là nó tạo cho việc tìm kiếm phòng trọ dễ dàng hơn. Mặt hạn chế là nó làm tăng tính phức tạp xã hội ở một dãy trọ có quá đông người thuê trọ

- Số người ở trong một phòng của dãy trọ, có $38 \%$ sinh viên ở một mình, $52 \%$ phòng ở 2 3 người, nhưng đa số là phòng ở 2 người, và $10 \%$ sinh viên ở phòng trên 3 người.

- Giá phòng đa số là trên 700.000 đồng/phòng chiếm $64 \%$, tiếp đến là phòng từ 500.000-700.000 đồng/phòng chiếm 32\%, có rất ít phòng giá dưới 500.000 đồng $(4 \%)$. Ta thấy giá phòng khá cao so với mức sống của sinh viên, và đang có xu hướng tăng thêm, trong khi mức sống của sinh viên đang khá thấp chỉ từ 1,5- 2 triệu đồng/tháng.

- Về các dịch vụ đáp ứng của phòng trọ:

+ Vệ sinh khép kín chiếm 46\%

+ Có $68 \%$ dãy trọ có wifi, tương đương với mức khảo sát của sinh viên là $65 \%$, cho thấy nhu cầu tiếp cận thông tin internet của sinh viên rất cao. 

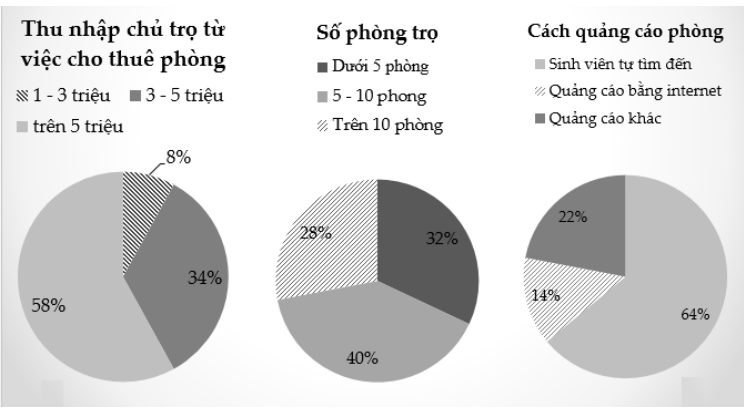

Hình 4. Biểu đồ một số thông tin về chủ trọ và phòng trọ.

+ Điện tùy theo từng dãy trọ, giao động từ 2.500-4.000 đồng/số, nhưng trung bình vẫn là 3000 đồng/số. Nhưng cũng có một số dãy trọ khoán cho sinh viên luôn theo mực dự tính mỗi tháng dùng hết 4 số nên khoán cho sinh viên nạp tiền điện mỗi tháng là 120.000 đồng/tháng.

+ Tương tự, nước cũng khoán trung bình là 50.000 đồng/người cho mỗi tháng.

+ Tất cả các dãy trọ đều có nội quy (98\%) chỉ có $2 \%$ dãy thấy nội quy là không quan trọng và cần thiết.

- Phương pháp giới thiệu phòng trọ đa số là treo biển quảng cáo để tự sinh viên đi tìm $(64 \%)$, chỉ có $14 \%$ là dùng internet để quảng cáo, và $22 \%$ là các cách quảng cáo phòng trọ khác, chính vì thế việc ứng dụng tìm phòng online là rất cần thiết và đáp ứng nhu cầu thiết thực nhất.

- Có 24\% dãy trọ có xu hướng mở rộng thêm, còn lại là không vì diện tích đất khu vực này khá là chật hẹp, $60 \%$ dãy trọ sẽ nâng cấp thêm và $34 \%$ dãy trọ có hướng đầu tư, phát triển thêm các dịch vụ hỗ trợ đời sống của sinh viên.

\section{3. Đề xuất biện pháp hỗ trợ sinh viên ngoại trú}

Với số lượng học sinh viên khá đông (khoảng 21.000 sinh viên chính quy), trong đó số sinh viên phải ở trọ chiếm hơn $90 \%$, điều kiện sống phần lớn của sinh viêncòn gặp nhiều khó khăn nên việc tìm được phòng trọ một cách nhanh chóng và lựa chọn mức giá hợp lí là mong muốn của phần lớn sinh viên Trường Đại học Vinh. Việc liên kết thông tin giữa chủ trọ với bộ phận quản sinh của nhà trường cũng là một yêu cầu cơ bản để giúp nhà trường nắm được thông tin của sinh viên ngoại trú cũng như hỗ trợ sinh viên trong việc tìm kiếm phòng trọ. Trên cơ sở nghiên cứu về thực trạng nhu cầu và khả năng đáp ứng phòng trọ cho sinh viên Trường Đại học Vinh, Nhà trường nên thực hiện một số biện pháp sau để nâng cao chất lượng công tác quản lý học sinh,sinh viên cũng như hỗ trợ cho sinh viên trong việc tìm kiếm thông tin phòng trọ một cách nhanh chóng, hiệu quả:

Thứ nhất, về công tác quản lý sinh viên ngoại trú: nhân rộng mô hình "quản lý học sinh, sinh viên" của phường Bến Thủy để tăng sự tương tác và liên kết giữa nhà trường với khu dân cư mà sinh viên sinh sống nhằm đảm bảo việc theo dõi điều kiện sống của sinh viên cũng như hỗ trợ kịp thời cho sinh viên trước những biến cố, rủi ro có thể xảy ra trong quá trình sinh sống và học tập tại địa bàn.

Thứ hai, về công cụ hỗ trợ sinh viên tìm kiếm phòng trọ:

- Cần cải tiến phiếu đánh giá sinh viên nội, ngoại trú [8] để khai thác tối đa nguồn thông tin về phòng trọ trên cơ sở các nội dung đã có. Trên mẫu phiếu cần yêu cầu sinh viên điền đầy đủ các thông tin về phòng trọ như: địa chỉ, số điện thoại của chủ trọ, số phòng, giá phòng, giá điện, giá nước, loại phòng...

- Cần đầu tư xây dựng bản đồ trực tuyến trên cơ sở nguồn dữ liệu từ phiếu điều đánh giá nội, ngoại trú sinh viên có khảo sát, kiểm tra trên thực tế. Việc xây dựng bản đồ trực tuyến cung cấp thông tin phòng trọ cho sinh viên Trường Đại học Vinh là một giải pháp hữu hiệu hỗ trợ cho các nhà quản lý thấy được tổng thể thực trạng về sự phân bố sinh viên ngoại trú của trường để đưa ra các đề xuất và giải pháp quản lí tốt hơn, đồng thời hỗ trợ cho các bạn sinh viên nắm bắt rõ hơn các thông tin phòng trọ (địa chỉ, số điện thoại chủ trọ, giá phòng, loại phòng...) giúp cho việc tìm kiếm phòng online dễ dàng hơn. 


\section{Kết luận}

Trường Đại học Vinh là một trường đại học đa ngành với số lượng sinh viên rất đông. Mặc dù nhà trường đã có nhiều nỗ lực trong việc xây dựng cơ sở hạ tầng phục vụ cho nhu cầu ăn ở của sinh viên (Kí túc xá, nhà ăn, khu chung cư của sinh viên...), nhưng với số lượng sinh viên khá lớn nên khả năng đáp ứng nhu cầu ở cho sinh viên còn nhiều hạn chế. Do đó, hầu hết sinh viên Trường Đại học Vinh đều phải ở bên ngoài nên nhu cầu thuê phòng trọ của sinh viên rất lớn. Tuy nhiên, qua khảo sát điều tra có thể thấy sinh viên phần lớn đến từ nhiều địa phương khác nhau với hoàn cảnh sống của phần lớn sinh viên còn nhiều khó khăn, khả năng tìm kiếm phòng trọ của sinh viên cũng như các phương pháp tiếp cận phòng trọ cho sinh viên còn nhiều hạn chế, chủ yếu là bằng con đường tự đi tìm. Nhiều sinh viên cảm thấy khó khăn trong việc tìm kiếm và lựa chọn phòng trọ phù hợp với hoàn cảnh của mình. Khả năng đáp ứng nhu cầu cho thuê trọ của sinh viên của địa bàn xung quanh trường đại học Vinh ở mức khá, chất lượng phòng trọ ngày càng được nâng cao với các dịch vụ đi kèm (điện, nước, công trình phụ khép kín, wifi...), tuy nhiên, phần lớn các chủ trọ chỉ treo biển quảng cáo trước cửa chứ không có các biện pháp tốt hơn để giúp sinh viên tiếp cận với phòng trọ nhanh hơn. Do đó, cần phải có những biện pháp cụ thể và có sự phối hợp giữa nhà trường với địa bàn dân sinh để hỗ trợ sinh viên trong việc tìm kiếm thông tin phòng trọ một cách dễ dàng, hiệu quả hơn.

\section{Tài liệu tham khảo}

[1] Trường Đại học Vinh, Báo cáo tổng kết năm học Trường Đại học Vinh, năm 2014 - 2015.

[2] Phòng Công tác Chính trị học sinh - sinh viên, Trường Đại học Vinh, Báo cáo tổng kết công tác học sinh, sinh viên năm học 2014 - 2015.

[3] Thống kê học sinh, sinh viên Đại học Vinh năm học 2014 - 2015.

[4] UBND phường Trường Thi, Báo cáo kinh tế- xã hội phường Trường Thi, 2014.

[5] UBND phường Bến Thủy, Báo cáo kinh tế- xã hội phường Bến Thủy, 2014.

[6] UBND phường Trung Đô, Báo cáo kinh tế- xã hội phường Trung Đô, 2014.

[7] Tỉnh Đoàn Nghệ An, Danh sách điều tra phòng trọ thành phố Vinh, năm 2015.

[8] Khoa Địa lí - QLTN, Trường Đại học Vinh, Hồ sơ sinh viên ngoại trú năm 2015.

\title{
Investigation Needs and the Ability to Search motel Rooms for Vinh University Students and Proposed Solutions to Support Students in Finding the Motel Room
}

(Look at the sample from student Geography Teachers)

\author{
Luong Thi Thanh Vinh, Nguyen Thanh Phong \\ Geography - Natural Resource Management Department, Vinh University, \\ 182 Le Duan, Vinh, Nghe An, Vietnam
}

\begin{abstract}
Based on the survey needs and the ability to search motel rooms for Vinh University students, the article has analyzed characteristics Vinh University students as well as the needs and the ability to search dorm room. At the same time, the paper also examines the ability to meet the rented room of the surrounding areas from Vinh University to propose solutions that support students seeking dorm room quickly and conveniently.
\end{abstract}

Keywords: Student, Motel room, Vinh University. 